\title{
Análise geoambiental da região litorânea da divisa dos estados do Piauí e Ceará
}

Geoenvironmental analysis of the coastal region of the border between the states of Piauí and Ceará

\author{
Moraes $^{1}$, M. V. A. R.
}

valdirene@ufpi.edu.br

\begin{abstract}
Resumo
A presente pesquisa analisou as unidades ambientais da região litorânea na divisa dos estados do Piauí e Ceará, que corresponde ao complexo estuarino dos rios Timonha (CE) e Ubatuba (PI). A metodologia adotada foi a análise Geossistêmica dos atributos ambientais. Foi utilizado banco de dados vetoriais do IBGE (2013); ANA (2016); IBGE-EMBRAPA (2001) e imagens do sensor SRTM, os dados foram trabalhados em ambiente SIG com o uso do software ArcGIS 9.3. Os resultados foi o mapeamento geológico, solos, drenagem e o MDT, no qual foram fundamentais para a compartimentação ambiental da área, detalhando a ecodinâmica da mesma.
\end{abstract}

Palavras-chave: SRTM. Compartimentação Ambiental. Ecodinâmica.

\begin{abstract}
This research analyzed the environmental units of the coastal region on the border of the states of Piauí and Ceará corresponding to the estuarine complex of Timonha rivers (CE) and Ubatuba (PI). The methodology adopted was the geosystemic analysis of environmental attributes. It was used vector database IBGE (2013); ANA (2016); IBGE-EMBRAPA (2001) and pictures SRTM sensor, the data were worked in GIS using ArcGIS 9.3 software. The results were geological mapping, soil, drainage and DEM, which were fundamental for environmental compartmentalisation of the area, detailing ecodynamics the same.
\end{abstract}

Keywords: SRTM. Environmental compartmentation. Ecodynamics

\section{INTRODUÇÃO}

A região litorânea é um ambiente que se encontra em constante mudança, seja por fatores antropogênicos ou naturais, aspecto que lhe atribui à condição de dinâmica constante. Nessas áreas tem se concentrado os principais centros urbanos, ocasionando uma intensa interferência humana nos ecossistemas costeiros, consequentemente, resultando nos mais variados impactos ambientais.

As áreas costeiras apresentam grande variabilidade temporal e espacial, comportando-se como um sistema ambiental instável, em função de uma série de processos geológicos continentais e marinhos, os quais são fundamentalmente controlados por fatores meteorológicos. (BAPTISTA NETO et al., 2004). Bernardes e Ferreira (2003) abordam que o mundo vem passando por um importante processo de reorganização, onde as questões ambientais tentam resgatar sua essência frente às relações sociedade/natureza. Baptista et al. (2004) retomam chamando a atenção que a urbanização e a exploração irracional dos recursos naturais são consequências do crescimento acelerado de metrópoles e cidades localizadas em planície litorânea.

O Brasil tem uma das maiores extensões de manguezais do mundo, margeando estuários, lagunas e enseadas, desde o Cabo Orange no Amapá até o Município de Laguna, em Santa Catarina. 
Os mangues abrangem uma superfície total de mais de $10.000 \mathrm{~km}^{2}$, a grande maioria na Costa Norte(GUERRA, 1988). O manguezal é um ecossistema particular, que se estabelece nas regiões tropicais de todo o globo. Origina-se a partir do encontro das águas doce e salgada, formando a água salobra. Este ambiente apresenta água com salinidade variável, sendo exclusivo das regiões costeiras. Os mangues localizam-se em terrenos baixos, junto à costa, sujeito às inundações das marés. Esses terrenos são, na quase totalidade, constituídos de vasas (lamas) de depósitos recentes. (GUERRA, 1988).

No Brasil, os mangues são protegidos por legislação federal, devido à importância que representam para o ambiente marinho. São fundamentais para a procriação e o crescimento dos filhotes de vários animais, como rota migratória de aves e alimentação de peixes. Além disso, colaboram para o enriquecimento das águas marinhas com sais nutrientes e matéria orgânica. No passado, a extensão dos manguezais brasileiros era muito maior: muitos portos, indústrias, loteamentos e rodovias costeiras foram desenvolvidos em áreas de manguezal, ocorrendo uma degradação do seu estado natural.

O presente estudo teve como objetivo analisar as condições geoambientais da região litorânea, que comporta uma extensa área de manguezal no estuário dos rios Timonha (PI) e Ubatuba (CE) na divisa dos estados do Piauí e Ceará, abrangendo os municípios de Chaval, Barroquinha, Camocim, Uruoca e Granja no estado do Ceará e os municípios de Cajueiro da Praia, Luís Correia, Bom Princípio do Piauí e Cocal no estado do Piauí. O estudo sobre a dinâmica costeira tem toda uma complexidade por envolver diversos fatores ambientais e antropogênicos que se inter-relacionam. Segundo Vasconcelos (2005), a zona costeira é lugar de pressão demográfica e econômica, sendo, portanto, fonte de recursos naturais utilizados pelas populações humanas. A combinação desses fatores está no cerne de muitos conflitos de usos e interesses atuais e futuros. Araújo e Freire (2007) abordam que a expansão urbana, atividades comerciais e pesqueiras podem acelerar a ocupação desordenada de áreas como às planícies fluviomarinhas, fluviais e áreas de dunas, ocasionando o desequilíbrio ambiental.

Para a análise ambiental, torna-se fundamental o uso de técnicas que permitam processar os dados com rapidez e também com certa precisão. O uso das ferramentas do geoprocessamento é indispensável para conhecer a distribuição e comportamento das unidades ambientais, bem como delimitar as formas de uso e ocupação do solo. Trentin et. al. (2012) citado por Moraes e Lima (2015) reforçam acerca da importância dos SIGs, descrevendo que nas análises ambientais, o uso das geotecnologias proporciona uma maior agilidade na realização de levantamento e processamento das informações, na integração, espacialização dos dados e elaboração dos resultados. Portanto, além da importância de manipular os dados existentes é gerar novas 
informações a partir destes. Os Sistemas de Informações Geográfica (SIGs) constitui-se numa ferramenta eficaz, sendo capaz de não somente armazenar e manipular os dados georreferenciados, como também permite a inclusão, exclusão, substituição e cruzamentos das mais variadas informações.

\section{METODOLOGIA}

\subsection{Fundamentação teórico-metodológico}

Para o embasamento teórico-metodológico foram utilizadas contribuições de Bertrand, (1972), os princípios da ecodinâmica de Tricart (1977), Sotchava (1976), bem como contribuições de Souza (1993, 1994, 2000, 2006), aplicando a teoria geossistêmica no estado do Ceará. Para este estudo também foi adotado a abordagem sistêmica de Rodriguez et al. (2004) que está baseada no princípio da interdisciplinaridade, que possibilita a identificação das alterações naturais por ações antrópicas de acordo com a metodologia da Geoecologia da Paisagem.

Para Bertrand (1972) a paisagem é o resultado da combinação da dinâmica ambiental com os fatores físicos e antrópicos no qual se interagem para compor um único "conjunto" que permanece em constante evolução. Na concepção ambiental de Rodriguez, Silva e Cavalcanti (2004) a visão sistêmica, holística e dialética exige da relação natureza/sociedade, com base na ideia da existência de sistemas ambientais que se inter-relacionam. A metodologia adotada por esses autores tem uma base sistêmica, que contribui para uma compreensão geral da dinâmica natural e dos aspectos antrópicos, que proporciona a elaboração de teoria e metodologia para o planejamento ambiental.

A classificação da ecodinâmica do meio ambiente foi adaptada a esta área de estudo segundo Tricart (1977) através dos meios morfodinâmicos: os meios estáveis, os de transição e os fortemente instáveis, que segundo esse autor, classificam-se como: meios estáveis: possuem uma estabilidade pedogenética antiga em função da fraca atividade do potencial erosivo e também pela ação antrópica onde o balanço entre os processos morfogenéticos e processos pedogenéticos são francamente favorável a pedogênese havendo um equilíbrio entre os fatores do potencial ecológico e fatores de exploração biológica; meios de transição: a dinâmica do ambiente é marcada pela preponderância de processos morfogenéticos ou de processos pedogenéticos, podendo favorecer uma ou outra condição, que no caso de pedogênese, passa-se aos meios estáveis; no caso de morfogênese, passa-se aos meios instáveis; meios fortemente instáveis: pedogênese praticamente nula; ausência ou extrema rarefação d cobertura vegetal; incidência acentuada dos processos erosivos. Crepani et al. (2001) citado por Corrêa (2011) estabelece valores para esse equilíbrio, 
assim a paisagem pode ser analisada quanto a sua estabilidade, avaliando dessa forma, a sua estrutura morfológica.

Souza (2000) classifica a sustentabilidade das unidades naturais, sob o ponto de vista do meio ambiente e dos recursos naturais, onde agrupa em quatro categorias: sustentabilidade muito baixa: a degradação ambiental é alta e adquire características irreversíveis, considerando-se nestes ambientes a vulnerabilidade alta; sustentabilidade baixa: áreas com sérios problemas quanto à capacidade produtiva dos recursos naturais renováveis onde se nota a degradação ambiental ainda em grandes proporções, caracterizando-se nestes ambientes vulnerabilidades alta; sustentabilidade moderada: áreas com razoável capacidade produtiva dos recursos naturais, ocorrendo nestas áreas vulnerabilidades moderadas; sustentabilidade alta: áreas dotadas de boa capacidade produtiva dos recursos naturais e com limitações que podem ser mitigadas com aplicações de tecnologias simples, possuindo, portanto, vulnerabilidade baixa.

As geotecnologias tornaram-se de grande importância em estudos ambientais, o que pode ser constatado em diversos estudos como em Sena, Santiago Neto e Leite (2012) que reforçam que o geoprocessamento é uma ferramenta importância para o "monitoramento da biodiversidade, devido a capacidade coleta de dados para diversos estudos, bem como realizar análises complexas, ao integrar dados de diversas fontes de dados".

Para Argento (2009, p. 384) citado por Sundfeld, Silva e Costa (2011):

É fundamental, ter em mente que as modernas tecnologias disponíveis para elaboração de mapeamentos temáticos, por si só, não garantem produto eficiente, já que elas servem, apenas, de apoio para melhorar a resolução do mapa final. A utilização dessa metodologia traz embutida a elaboração de um conjunto de cartas temáticas, em que o mapeamento geomorfológico se traduz numa carta fundamental para ser entrecruzada a outros planos de informações e gerar cenários ambientais.

O presente estudo vem com a proposta de analisar de forma integrada os atributos geoambientais da região litorânea da divisa dos estados do Piauí e Ceará, com o auxílio das geotecnologias (Sensoriamento Remoto, Sistemas de Informações Geográficas (SIG) e Geoprocessamento).

\subsection{Materiais e métodos}

Para realização desta pesquisa buscou-se referências relacionadas a temática de análise ambiental de regiões litorâneas, especialmente estudos que utilizaram tecnologias como sensoriamento remoto e geoprocessamento em suas análises, como Dias (2005); Araújo (2007); Araújo e Freire (2007); Araújo e Freire (2008); Moraes (2012); Santos et al. (2014); Moreira, Costa, Medeiros (S.D); Moraes e Lima (2015); Costa, Moraes e Portela (2016); Moraes, Manso e Freire 
(2015a); Moraes, Manso e Freire (2015b); Moraes et al. (2015); Portela et al. (2014); Corrêa (2011), dentre outros.

Foram utilizados banco de dados vetoriais do IBGE (2013) para a delimitação dos municípios do Ceará e Piauí, bem como dos estados; dados do IBGE-EMBRAPA (2001) para a obtenção dos dados referentes as classes de solos; classificação geológica foi obtida através dos arquivos vetoriais disponibilizados pela CPRM (2003); a delimitação das principais bacias e subbacias hidrográficas da área foi utilizado os dados disponibilizados pela ANA (2016).

Foram utilizadas as folhas 03S-42-ZN e 02S-42-ZN do satélite Shuttle Radar Topography Mission (SRTM), no qual o mesmo é uma cooperação entre a National Aeronautics and Space Administration (NASA) e a National Imagery and Mapping Agency (NIMA) dos Estados Unidos. A missão foi designada para produzir Modelo Digital de Terreno (MDT), da superfície terrestre entre os paralelos $60^{\circ} \mathrm{N}$ e $56^{\circ}$ de latitude Sul, com uma resolução espacial de 30m (FARR; KOBRICK, 2000).

Os dados SRTM possibilitam a elaboração de modelos digitais de elevação, imagens fundamentais nos estudos do relevo, no qual foram gerados os mapas hipsométrico, rede de drenagem e delimitação de bacias hidrográficas através do software ArcGIS 9.3, disponibilizado no Laboratório Geoambiente da Universidade Federal do Piauí. Inicialmente as imagens SRTM foram transformadas de 32 bits para 16 bits, reprojetados para o Datum WGS1984 24S, em seguida foram extraídas as curvas de nível para uma equidistância de 10 metros, para isso utilizou-se a ferramenta countour da extensão $3 D$ Analyst do software citado. A partir das curvas de nível, foi gerado o MDT, utilizando a ferramenta Create TIN, na extensão 3D Analyst, Data Management, TIN. O TIN foi gerado em 20 classes, para que fosse possível analisar as diferenças de relevo, partindo da região litorânea sentido Planalto da Ibiapaba.

Para gerar a rede de drenagem a partir da imagem SRTM, com os ajustes processados (16 bits e reprojetadas para o Datum WGS1984 24S) foram utilizadas a ferramenta Spatial Analyst Hydrology e demais funções para o processamento e geração da delimitação de bacias hidrográficas (Flow Direction - Sink - Fill - Flow Accumulation) após isso, foi executado as ferramentas (Spatial Analyst - Map Algebra - Raster Calculator) para definir os padrões de drenagem; com a ferramenta Stream to Feature a drenagem foi convertida para shapefile; e por último foi utilizado a ferramenta Basin para a delimitação das bacias e sub-bacias hidrográficas.

O mapa geológico e o mapa de solos foram gerados a partir de dados vetoriais obtidos através do banco de dados no site do IBGE e IBGE-EBRAPA, respectivamente. A partir desses bancos de dados foram gerados em ambiente SIG os mapas de geologia e de solos da área. 
Com a aplicação de técnicas de realces e transformações de imagens, conseguiu-se obter melhorias significativas na qualidade visual dos produtos de sensoriamento remoto, permitindo a utilização dos mesmos no desenvolvimento do trabalho, por exemplo, a reinterpretação a delimitação das unidades ambientais.

\section{RESULTADOS E DISCUSSÃO}

3.1 Caracterização dos aspectos geoambientais da área

A área em estudo abrange a faixa litorânea na divisa dos estados do Piauí e Ceará, englobando o município de Cajueiro da Praia e parte dos municípios de Luís Correia, Bom Princípio do Piauí e Cocal no estado do Piauí; no Ceará abrange os municípios de Barroquinha e Chaval e parte dos municípios de Camocim, Uruoca e Granja (Figura 1). As condições climáticas dos municípios da área apresentam temperaturas mínimas em torno de $22^{\circ} \mathrm{C}$ e máximas de $36^{\circ} \mathrm{C}$, com clima quente tropical. A precipitação pluviométrica média anual possui isoietas entre 800 a $1.600 \mathrm{~mm}$, com cerca de 5 a 6 meses como os mais chuvosos e período seco no restante do ano. $\mathrm{O}$ trimestre mais úmido é o formado pelos meses de fevereiro, março e abril (AGUIAR, 2004)

A Planície Litorânea é composta por feições morfológicas como: a faixa praial, campo de dunas móveis e paleodunas, que são resultantes de processos de acumulação, propiciadas pelas ações eólica, marinha e fluvial, que agem isoladamente ou em conjunto.

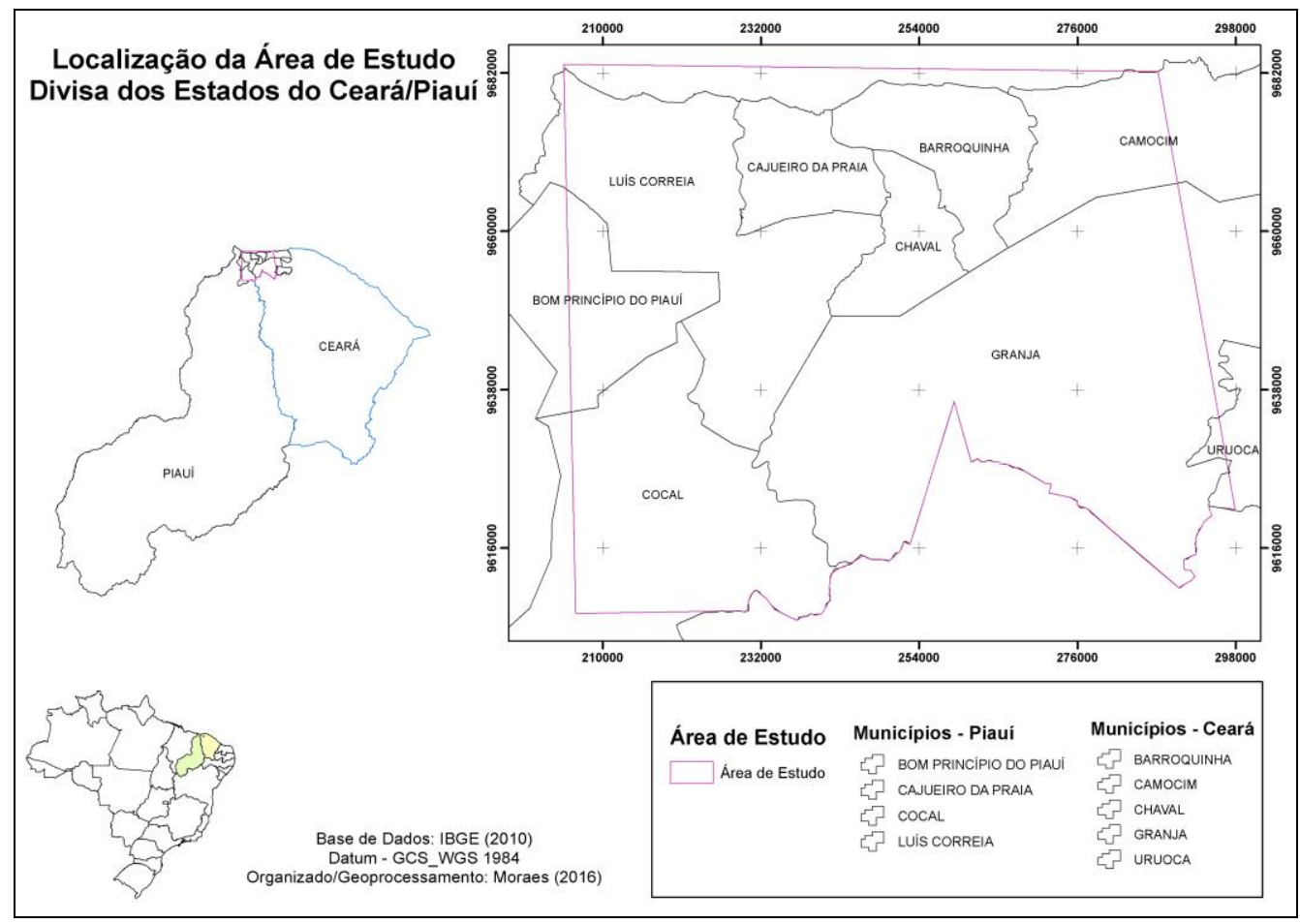

Figura 01. Localização da área. Fonte: Organizado Moraes (2016). 
A geologia da área está representada por nove formações sedimentares (Figura 2): o Grupo Barreiras apresenta-se na área com exposições de arenito, conglomerado, intercalados de siltito e argilito e compreende parte de todos os municípios estudados; as dunas e os depósitos litorâneos localizam-se nos municípios de Luís Correia, Cajueiro da Praia, Barroquinha, Camocim e Chaval, na Figura 3 pode-se observar o relevo dessa unidade geológica, que compreendem, principalmente, a superfícies tabulares reelaboradas e relevo plano com partes suavemente onduladas, altitudes variando de 50 a 145 metros e faixa litorânea plana. No município de Chaval, pode-se observar a transição entre os terrenos do embasamento cristalino com os sedimentos recentes da Formação Barreiras e da planície flúvio-marinha dos rios Timonha e Ubatuba (Figura 2 e 4) (DIAS, 2005).

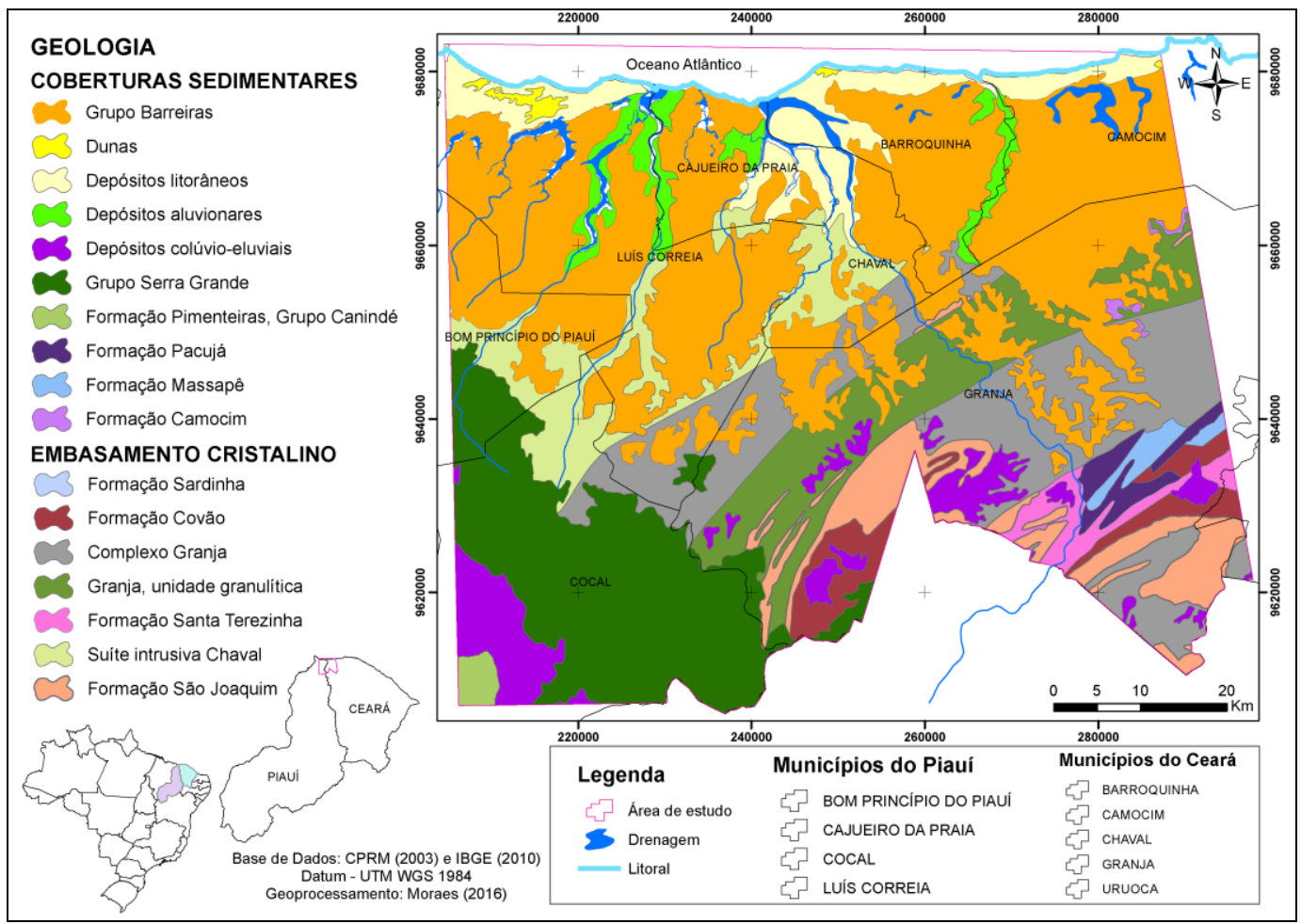

Figura 02. Aspectos geológicos e geomorfológicos da área. Fonte: Organizado Moraes (2016).

Os depósitos aluvionares ocorrem ao longo dos principais rios conforme observado na Figura 2 e 3. Os depósitos colúvio-eluviais que agrega areia, argila, cascalho e laterito apresenta-se nos municípios de Cocal e Granja; o Grupo Serra Grande ocupa parte do município de Cocal; Formação Pimenteiras e Grupo Canindé abrange parte do município de Cocal; a Formação Pacujá; Formação Massapê e a Formação Camocim ocupa parte do município de Granja.

Os depósitos litorâneos conforme mostrado na Figura 2, agrega tanto os campos de dunas da região litorânea como a planície flúvio-marinha dos rios Timonha e Ubatuba. A rede de drenagem da área está representada principalmente pelo estuário dos rios Timonha (CE) e Ubatuba (PI) na divisa dos estados do Ceará e Piauí, por duas sub-bacias, a do rio Remédios no Ceará e do rio Camurupim no 
Piauí, como se observa na Figura 3. A maior bacia hidrográfica na área pesquisada está representada pela bacia dos rios Timonha e Ubatuba, cuja planície flúvio-marinha ocupa uma área $68 \mathrm{~km}^{2}$, encaixada entre os terrenos da Formação Barreiras e do Embasamento Cristalino (DIAS, 2005).

O Embasamento Cristalino está representado na área em sete formações: a de maior expressão é o Complexo Granja, constituído de ortognaisse e migmatito, abrange parte dos municípios de Granja, Chaval, Barroquinha, Luís Correia e Cocal. A Formação intrusiva Chaval abrange cinco municípios: Bom Princípio do Piauí, Luís Correia, Chaval, Cajueiro da Praia e Cocal; a Formação Covão e São Joaquim aparece no município de Granja e a Formação Granja e Santa Terezinha está compartimentada no município de Granja (Figura 2 e 3).

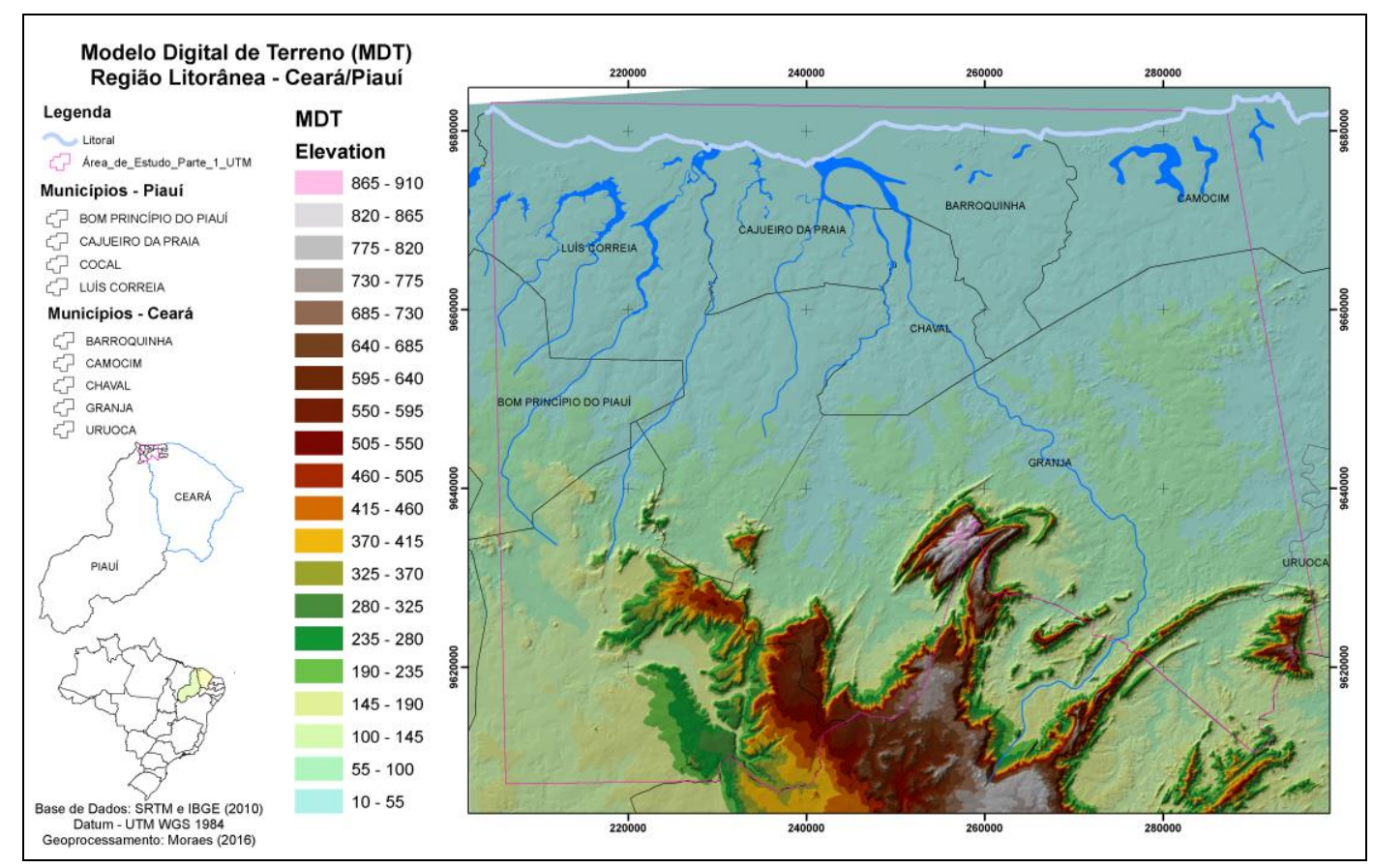

Figura 03. Aspectos geológicos e geomorfológicos da área. Fonte: Organizado Moraes (2016).

Os solos mais representativos da área de estudo é o Argissolo Vermelho-Amarelo ocorrendo principalmente em área de relevos mais acidentados e dissecados (EMBRAPA, 2016a), correspondendo principalmente à região da Formação Barreiras (Figura 2). Na faixa litorânea encontram-se os Neossolos Flúvicos, caracterizados como solos minerais não hidromórficos, pertencentes aos sedimentos recentes do período Quaternário. São formados por sobreposição de camadas de sedimentos aluviais recentes sem relações pedogenéticas entre elas, devido ao seu baixo desenvolvimento pedogenético (EMBRAPA, 2016b), abrangendo parte dos municípios litorâneos.

Os Neossolos Quartzarênicos ocorrem em relevo plano ou suave ondulado (Figura 4, apresenta-se com textura arenosa ao longo do perfil e possui cor amarelada de forma uniforme localizado logo abaixo do horizonte A (EMBRAPA, 2016c). Os Neossolos Litólicos (Figura 4) ocorre somente no município de Granja, caracteriza-se como solos rasos, que geralmente o seu 
perfil não ultrapassa $50 \mathrm{~cm}$, estando associados normalmente a relevos mais declivosos (EMBRAPA, 2016d). Pode-se observar na Figura 4 que a ocorrência desse tipo de solo, está representado por áreas de relevo montanhoso que variam de 190 a 600 metros.

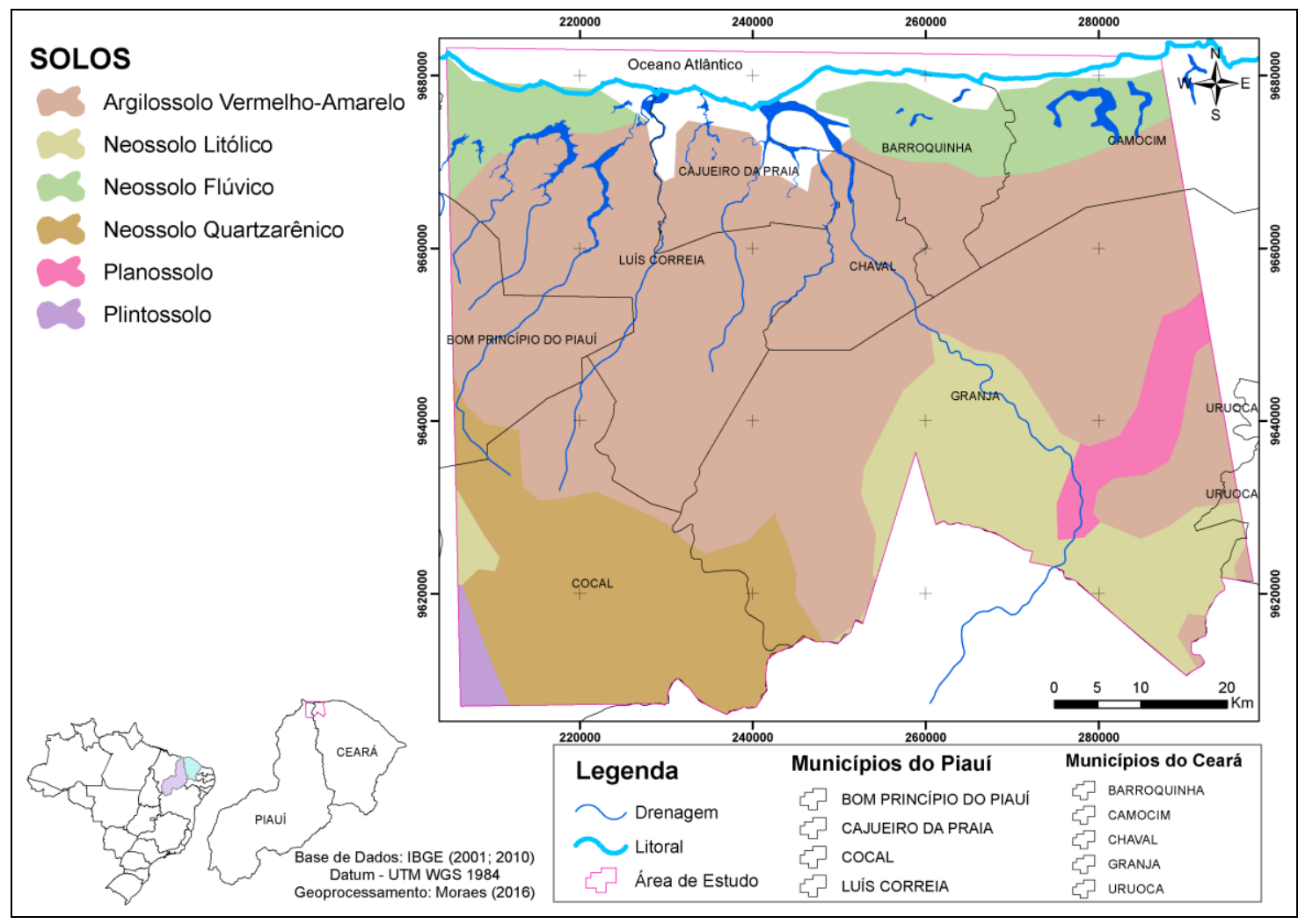

Figura 04. Solos da área. Fonte: Organizado Moraes (2016).

Os planossolos (no município de Granja) e os plintossolos (no município de Cocal) aparecem em menor proporção, os primeiros (EMBRAPA, 2016e) são solos minerais que apresentam perda de argila que possui concentração de argila nos horizontes subsuperficiais, e ocorrem em áreas de relevo plano ou suavemente ondulado (Figura 3 e 4), Sousa e Oliveira (2011) aborda que a declividade influencia no transporte de material particulado de solo e em áreas altas declividades apresentam suscetibilidade ao desenvolvimento de processos erosivos. Os Plintossolos são solos fortemente ácidos, podem apresentar saturação por bases baixa (distróficos) ou alta (eutróficos), predominando os de baixa saturação (EMBRAPA, 2016f).

\subsection{Compartimentação geoambiental}

A análise ambiental foi realizada levando-se em consideração as unidades temáticas estudadas, com o propósito de agrupá-las segundo as especificidades quanto às condições mútuas entre os fatores geoecológicos (geologia, geomorfologia, clima e drenagem) e os fatores de exploração antrópica (solos e vegetação). A análise desses atributos permitiu compartimentar a 
região litorânea da divisa dos estados do Piauí e Ceará, revelando as potencialidades e limitações de uso dos recursos naturais dessa área. De acordo com Penteado (1980) a paisagem faz parte de um sistema que conforme é um conjunto de objetos ou atributos e das suas relações, organizados para executar uma função particular. Ainda segundo o mesmo autor os Geossistemas como formações naturais que experimentam o impacto dos ambientes: social, econômico e técnico. O Geossistema deve assim ser, discretamente isolado do seu conjunto maior para ser delimitado e definido como um conjunto unitário complexo.

Para a definição das categorias ecodinâmicas na área de estudo, foi utilizada uma adaptação da classificação proposta por Tricart (1977). Esse elenco de correlações, análises e sínteses (Quadro 1), permitiram compartimentar a área em unidades territoriais homogêneas de acordo com Souza (2000).

Para realizar a compartimentação ambiental da área, consistiu em foram realizadas interações temáticas através de sucessivos níveis de síntese, de acordo com as relações de causa e efeito. Esse mecanismo de correlação interdisciplinar conduziu à identificação da estrutura e da dinâmica dos espaços diferenciados para a conclusão da análise, onde esses dados foram estudados de forma integrada com o estudo as unidades ambientais, resultando na ecodinâmica da área de estudo.

Quadro 01. Compartimentação das unidades geoambientais da área em estudo. Fonte: Souza (2000).

\begin{tabular}{|c|c|c|c|}
\hline UNIDADES & NATURAIS & Características naturais & Ecodinâmica \\
\hline $\begin{array}{l}\text { Planície } \\
\text { litorânea }\end{array}$ & $\begin{array}{ll}\text { - } & \text { Planície fluviomarinha } \\
\text { - Campo de dunas } \\
& \text { móveis } \\
\text { - } & \text { Campo de dunas } \\
& \text { semifixas e fixas }\end{array}$ & $\begin{array}{l}\text { Linha de costa com dunas sob intensa } \\
\text { ação eólica. Planície fluviomarinha } \\
\text { com solos Neossolos Flúvicos e } \\
\text { vegetação do complexo litorâneo. }\end{array}$ & $\begin{array}{l}\text { Ambientes instáveis } \\
\text { fortemente instáveis } \\
\text { vulnerabilidade alta } \\
\text { ocupação. }\end{array}$ \\
\hline $\begin{array}{l}\text { Tabuleiros } \\
\text { Litorâneos }\end{array}$ & $\begin{array}{ll}\text { - } & \text { Tabuleiros arenosos } \\
\text { - } & \text { Tabuleiros areno- } \\
& \text { argilosos }\end{array}$ & $\begin{array}{l}\text { Superfície predominantemente plana, } \\
\text { com declividade suave em direção ao } \\
\text { mar, presença de lagoas com } \\
\text { vegetação de tabuleiros modificados } \\
\text { pelas intervenções antrópicas. }\end{array}$ & $\begin{array}{l}\text { Ambiente estável com baixa } \\
\text { vulnerabilidade. Favorável a } \\
\text { expansão urbana e plantação } \\
\text { de culturas diversificadas. }\end{array}$ \\
\hline $\begin{array}{l}\text { Planícies } \\
\text { fluviais }\end{array}$ & $\begin{array}{l}\text { - Planície fluvial dos rios } \\
\text { Timonha e Ubatuba; } \\
\text { - Planície fluvial do rio } \\
\text { Remédios; } \\
\text { - Planície fluvial do rio } \\
\text { Camurupim. }\end{array}$ & $\begin{array}{l}\text { Áreas planas resultantes da } \\
\text { acumulação fluvial sujeitas a } \\
\text { inundaçôes periódicas que margeiam } \\
\text { as calhas dos rios. Possuem solos } \\
\text { profundos, com predominância de } \\
\text { carnaúba margeando esses cursos } \\
\text { hídricos. A vegetação de carnaúba é } \\
\text { característica dessa área. }\end{array}$ & $\begin{array}{lc}\text { Ambientes de transição com } \\
\text { tendência à instabilidade e } \\
\text { com } & \text { vulnerabilidade } \\
\text { moderada. } & \end{array}$ \\
\hline $\begin{array}{l}\text { Planaltos } \\
\text { Sedimentares } \\
\text { e Depressões } \\
\text { periféricas }\end{array}$ & $\begin{array}{l}\text { - Planalto da Ibiapaba } \\
\text { - Depressão Periférica do } \\
\text { Ceará }\end{array}$ & $\begin{array}{l}\text { Superfícies planas ou suavemente } \\
\text { inclinadas em função da assimetria } \\
\text { topográfica, condicionadas por } \\
\text { estruturas geológicas de bacias } \\
\text { sedimentares. Caracterizados por } \\
\text { solos espessos e vegetação que varia } \\
\text { desde caatingas até matas } \\
\text { pluvionebulares e cerrados. }\end{array}$ & $\begin{array}{l}\text { Ambientes de transição com } \\
\text { tendência à estabilidade e } \\
\text { vulnerabilidade moderada nas } \\
\text { áreas de reverso imediato, } \\
\text { com relevos de baixos } \\
\text { declives. }\end{array}$ \\
\hline
\end{tabular}




\begin{tabular}{|c|c|c|c|}
\hline $\begin{array}{l}\text { Cristas, } \\
\text { Serras/Vertent } \\
\text { es Secas e } \\
\text { agrupamentos } \\
\text { de Inselbergs }\end{array}$ & $\begin{array}{l}\text { Inselbergs do } \\
\text { município de Granja }\end{array}$ & $\begin{array}{l}\text { Áreas de menores dimensões } \\
\text { dispersas pelas depressões sertanejas, } \\
\text { que são derivadas da erosão } \\
\text { diferenciada em setores de rochas } \\
\text { muito resistentes. Essas áreas } \\
\text { predominam a vegetação de caatinga. }\end{array}$ & $\begin{array}{l}\text { Ambiente fortemente instáveis } \\
\text { e vulnerabilidade alta à } \\
\text { ocupação. }\end{array}$ \\
\hline
\end{tabular}

\section{CONSIDERAÇÕES FINAIS}

O uso das geotecnologias foi de extrema importância para a concretização da presente pesquisa, a análise ambiental da região litorânea da divisa dos estados do Piauí e Ceará, abrangendo parte de nove municípios. As técnicas de geoprocessamento auxiliaram de forma precisa no manuseio dos bancos de dados e imagens de radar (SRTM) utilizados, mostrando agilidade e velocidade que estas ferramentas proporcionam nos estudos ambientais.

Com isso, pode-se mostrar espacialmente as características da área pesquisada, fazendo uma correlação entre os diversos fatores ambientais, que se inter-relacionam na dinâmica da paisagem, que ora se modificam por sua própria dinâmica, ora pela interferência antrópica. A partir da análise desse conjunto de fatores, pode-se sumarizar as unidades ambientais, caracterizando-as quanto a sua ecodinâmica e vulnerabilidade ambiental.

\section{REFERÊNCIAS}

AGUIAR, R. B. Projeto cadastro de fontes de abastecimento por água subterrânea, estado do Piauí: diagnóstico dos municípios do Piauí / Organização do texto [por] Robério Bôto de Aguiar [e] José Roberto de Carvalho Gomes. Fortaleza: CPRM - Serviço Geológico do Brasil, 2004.

ANA. Agência Nacional de Águas. Base de dados georreferenciados. Delimitação de Bacias

Hidrográficas. Disponível em: http://www.ana.gov.br/bibliotecavirtual/solicitacaoBaseDados.asp. Acesso em: 29/07/2016.

ARAÚJO, M. V. Análise ambiental da área estuarina do rio Acaraú - Ceará - Brasil. 2007. Dissertação de mestrado apresentado ao Programa de Pós-Graduação em Geologia do Departamento de Geologia da Universidade Federal do Ceará, Fortaleza, 2007. 130p.

ARAÚJO, M. V.; FREIRE, G. S. S. Utilização de geotecnologias: diagnóstico ambiental do rio Acaraú/CE como estudo de caso. Pesquisas em Geociências (Online), v. 34, p. 33-44, 2007.

ARAÚJO, M. V.; FREIRE, G. S. S. Análise ambiental e de uso e ocupação da Área de Proteção Ambiental do estuário do Rio Ceará, Fortaleza, Ceará. Revista de Geologia (Fortaleza), v. 21, p. 7-19, 2008.

BAPTISTA NETO, J. A. et al. Introdução a Geologia Marinha. Rio de Janeiro: Editora Interciência, 2004. 279 p.

BERNARDES, J. A.; FERREIRA, F. P. M. Sociedade e Natureza. In: Cunha, Sandra Baptista da Cunha; Guerra, Antonio José Teixeira (org.) A questão ambiental: diferentes abordagens. Rio de Janeiro: Bertrand Brasil, 2003. 248p.

BERTRAND, G. Paisagens e Geografia Física Global: Esboço Metodológico. Caderno de Ciências da Terra. $N^{\circ}$ 13. Instituto de geografia - USP, São Paulo, 1972. 
CORRÊA, L. C. Uso de geotecnologias e análise da paisagem na gestão ambiental: estudo de caso Dois Irmãos do Buriti, Mato Grosso do Sul. Dissertação de mestrado apresentado ao Programa de Pós-Graduação em Tecnologias Ambientais da Universidade Federal de Mato Grosso do Sul, 2011. 65p.

COSTA, S. S. L.; MORAES, M. V. A. R.; PORTELA, J.P. Compartimentação geoambiental do município de Demerval Lobão, Piauí. Revista de Geociências do Nordeste, v. 1, p. 21-37, 2016.

CPRM. Dados geológicos dos estados do Ceará e Piauí. 2003. Disponível em: http://geobank.cprm.gov.br/. Acesso em: 29/07/2016.

DIAS, C. B. Dinâmica do sistema estuarino Timonha/Ubatuba (Ceará - Brasil): considerações ambientais. Dissertação de mestrado apresentado ao Programa de Pós-Graduação em Ciências Marinhas Tropicais da Universidade Federal do Ceará. 2005, 146p.

EMBRAPA. Classificação dos solos. Disponível em: http://www.agencia.cnptia.embrapa.br/gestor/solos_tropicais/arvore/CONT000gn0pzmhe02wx5ok0liq1mqk 4130gy.html. Acesso em: 29/07/2016a.

EMBRAPA. Classificação dos solos. Disponível em: http://www.agencia.cnptia.embrapa.br/gestor/territorio_mata_sul_pernambucana/arvore/CONT000gt7eon7k 02wx7ha087apz246ynf0t.html. Acesso em: 29/07/2016b.

EMBRAPA. Classificação dos solos. Disponível em: http://www.agencia.cnptia.embrapa.br/gestor/solos tropicais/arvore/CONT000gn230xho02wx5ok0liq1mqtar ta66.html. Acesso em: 29/07/2016c.

EMBRAPA. Classificação dos solos. Disponível em: http://www.agencia.cnptia.embrapa.br/gestor/solos_tropicais/arvore/CONT000gn230xho02wx5ok0liq1mqxh k6vk7.html. Acesso em: 29/07/2016d.

EMBRAPA. Classificação dos solos. Disponível em: http://www.agencia.cnptia.embrapa.br/gestor/solos tropicais/arvore/CONTAG01 14 2212200611542.html. Acesso em: 29/07/2016e.

EMBRAPA. Classificação dos solos. Disponível em: http://www.agencia.cnptia.embrapa.br/gestor/solos_tropicais/arvore/CONTAG01_15_2212200611542.html. Acesso em: 29/07/2016f.

FARR, T. G. \& KOBRICK, M. 2000 Shuttle Radar Topography Mission produces a wealth of data. Amer. Geophys. Union Eos, 2000. v. 81, p. 583-585.

GUERRA, A. J. T. Dicionário Geológico-geomorfológico. 8. Ed. Instituto Brasileiro de Geografia e Estatística, 1988. 446p.

IBGE. Bases Cartográficas. Disponível em: http://mapas.ibge.gov.br/bases-e-referenciais/basescartograficas/malhas-digitais.html. Acesso em: 29/07/2016.

IBGE-EMBRAPA. Mapa de solos do Brasil. Rio de Janeiro. IBGE, 2001.

MORAES, M. V. A. R. Morfologia e sedimentologia do litoral e da plataforma continental interna do município de Acaraú - Ceará - Brasil. Tese de doutorado apresentado ao Programa de Pós-Graduação em Geociências da Universidade Federal de Pernambuco. 2012, 234p.

MORAES, M. V. A. R.; LIMA, I. M. de M. F. Análise Geomorfológica a Partir de Dados SRTM: Município de Teresina, Piauí. Revista Equador, v. 4, p. 951-960, 2015.

MORAES, M. V. A. R.; MANSO, V. A. V.; FREIRE, G. S. S. Morfologia e sedimentologia da plataforma continental interna do município de Acaraú Ceará Brasil. Revista de Geociências do Nordeste, v. 1, p. 1-21, 2015b.

MORAES, M. V. A. R.; MANSO, V. A. V. FREIRE, G. S. S. Comportamento Morfológico e Sedimentar Das Praias do Litoral Leste De Acaraú, Ceará. Revista Equador, v. 4, p. 1381, 2015 a. 
MORAES, M. V. A. R.; FREIRE, G. S. S.; MANSO, V. A. V. COSTA, S. S. L.; PORTELA, J.P. Multitemporal analisys of Coastline of Acaraú - Ceará - Brasil. Revista Brasileira de Geografia Física, v. 8, p. 981-989, 2015.

MOREIRA, M. L. O.; COSTA, H. F.; MEDEIROS, L. C. Integração de dados multifontes para mapeamentos temáticos. Disponível em:

http://www.sieg.go.gov.br/downloads/Integra\%C3\%A7\%C3\%A3o de dados multifontes para mapeament os tem\%C3\%A1ticos.pdf. Acesso em: 26/07/2016

PORTELA, J.P.; FREIRE, G. S. S.; MORAES, M. V. A. R.; SILVA, C. A. Evolução da morfologia costeira do litoral oeste de Icapuí - CE. Revista Geonorte, v. 10, p. 131-136, 2014.

RODRIGUEZ, J. M. M.; SILVA, E. D.; CAVALCANTI, A. P. B. Geoecologia da paisagem: uma visão geossistêmica da análise ambiental. Fortaleza: EDUFC, 2004.

SANTOS, N. G. dos; FRANCO, G. B.; MARQUES, E. A. G.; GOMES, R. L.; CHAGAS, C. da S. Proposta de zoneamento geoambiental para a bacia do rio Almada - Bahia. Revista de Geografia (UFPE) V. 31, No. $1,2014$.

SENA, F. T. N. S.; SANTIAGO NETO, B. J.; LEITE, A. C. S. Uso do geoprocessamento como subsídio à análise ambiental: imagem SRMT na geração dos mapas hipsómétrico e de declividade das bacias difusas da barragem Boa Esperança no estado do Piauí. IV Simpósio Brasileiro de Ciências Geodésicas e Tecnologias da Geoinformação. Anais... Recife - PE, 06- 09 de Maio de 2012 p. 003 - 005.

SOTCHAVA, V. A. O Estudo de Geossistemas. Métodos em Questão, 16. São

Paulo: IGEOG - USP, 1976. 51p.

SOUSA, S. B.; OLIVEIRA, I. J.; a compartimentação do relevo como ferramenta para o planejamento ambiental urbano: uma análise da Bacia Hidrográfica do Córrego Pedreira, município de Goiânia (GO). Ateliê Geográfico Goiânia-GO v. 5, n. 1 mar/2011 p.135-161.

SOUZA, M.J.N. Cobertura Vegetal e Antropismo no Estado do Ceará: uma abordagem utilizando imagens TM-LANDSAT. Fortaleza. FUNCEME, 1993. 34p.

. Projeto Áridas. In: Recursos Naturais e meio ambiente - v.2. FUNCEME, 1994. p. 143-162.

Bases geoambientais e esboço do zoneamento geoambiental do Estado do Ceará. In: Compartimentação Territorial e Gestão Regional do Ceará. Fortaleza: Editora FUCEME, 2000. 6 a 98p.

Panorama da Degradação ambiental, desertificação e entraves ao desenvolvimento sustentável do Ceará. In: Daniel R. de C. (org.). Desenvolvimento sustentável: desafios e discussões. Fortaleza: ABC Editora, 2006, p. 33-35.

SUNDFELD, I.; SILVA, R. L.; COSTA, S. M. F. Uso de geotecnologias para estudo do uso e ocupação do solo na sub Bacia do Córrego Pararangaba. XV Encontro Latino Americano de Iniciação Científica e XI Encontro Latino Americano de Pós-Graduação - Universidade do Vale do Paraíba. Disponível em: http://www.inicepg.univap.br/cd/INIC_2011/anais/arquivos/0832_1211_01.pdf. Acesso em: 29/07/2016.

TRICART, J. Ecodinâmica. Rio de Janeiro: FIBGE, 1977. 97p.

VASCONCELOS, F.P. Gestão Integrada da Zona Costeira. Editora Premius. Fortaleza, 2005. 88p.

Recebido em: 14/08/2016

Aceito para publicação em: 01/10/2016 